\title{
Artery of Davidoff and Schechter Supply in Dural Arteriovenous Fistulas
}

\author{
(D) K.D. Bhatia, DH. Kortman, (D). Wälchli, (DI. Radovanovic, (D) V.M. Pereira, and (D). Krings
}

\section{ABSTRACT}

SUMMARY: The artery of Davidoff and Schechter is a dural branch of the posterior cerebral artery that can supply the meninges close to the falcotentorial junction. It is usually not identified on angiography except when enlarged in the setting of a dural AVF or meningioma. The impact on treatment of the artery of Davidoff and Schechter supply to a fistula is not well-described in the literature. Our retrospective analysis of patients with dural AVFs treated at the Toronto Western Hospital between 2006 and 2018 identified 6 patients with dural AVFs receiving supply from artery of Davidoff and Schechter (of a total of 173 patients with dural AVFs). All patients were initially treated by transarterial embolization using liquid embolic agents. Three patients required a second endovascular procedure partly due to residual supply from artery of Davidoff and Schechter, and in all cases, angiographic cure was obtained. The treatment approach, challenges encountered, and potential complications of treating such fistulas are described.

ABBREVIATIONS: ADS = artery of Davidoff and Schechter; PCA = posterior cerebral artery; SCA = superior cerebellar artery

$\mathbf{T}$ he artery of Davidoff and Schechter (ADS) is a dural branch that arises from the posterior cerebral artery and supplies the falcotentorial junction. ${ }^{1}$ It is usually not identified on angiography except when enlarged in the setting of dural AVFs, ${ }^{2,3}$ meningiomas, ${ }^{4}$ or, rarely, cerebellar tumors. ${ }^{5}$ The ADS is the only dural branch of the posterior cerebral artery (PCA), ${ }^{1}$ and unlike most other arteries that provide dural supply, it has an intradural origin. ${ }^{6}$ The first description was by Wollschlaeger and Wollschlaeger, ${ }^{7}$ in 1965, based on postmortem barium angiography, and they named the artery to honor their mentors in neuroradiology. ${ }^{1}$

The ADS may originate from the superior surface of the P1-2 junction or the proximal P2 segment and extends posterolaterally across the ambient cistern between the superior cerebellar artery (SCA) superiorly and the trochlear nerve inferiorly,

Received September 25, 2019; accepted after revision November 20.

From the Division of Neuroradiology (K.D.B., H.K., V.M.P., T.K.), Joint Department of Medical Imaging, and Division of Neurosurgery (T.W., I.R., V.M.P., T.K.), Department of Surgery, Toronto Western Hospital, Toronto, Ontario, Canada; Department of Fundamental Neurobiology (T.W., I.R.), Krembil Research Institute, Toronto Western Hospital, University Health Network, University of Toronto, Toronto, Ontario, Canada; Group of CNS Angiogenesis and Neurovascular Link, and Physician-Scientist Program (T.W.), Institute for Regenerative Medicine, Neuroscience Center Zurich, Zurich, Switzerland; Department of Health Sciences and Technology (T.W.), Swiss Federal Institute of Technology, Zurich, Zurich, Switzerland; and Division of Neurosurgery Program (T.W.), University Hospital Zurich, Zurich, Switzerland.

Please address correspondence to Kartik Dev Bhatia, MD, Division of Neuroradiology, Level 3, Toronto Western Hospital, 399 Bathurst St, Toronto, M5T 2S8, ON, CANADA; e-mail: Kartik.bhatia@uhn.ca

Indicates article with supplemental on-line tables.

http://dx.doi.org/10.3174/ajnr.A6380 adjacent to the free edge of the tentorium. ${ }^{1}$ It supplies a 3- to $4-\mathrm{cm}$ width region on the inferior surface of the posterior medial tentorium as it approaches the falcotentorial junction, ${ }^{1,7}$ reinforcing the more anterior supply from the artery of Bernasconi and Cassinari (a branch of the meningohypophyseal trunk). ${ }^{6,7}$ Uniting with its contralateral partner at the falcotentorial junction, the ADS then pierces the dura and extends superiorly along the falx cerebri toward its attachment with the superior sagittal sinus (Fig 1). ${ }^{1,8}$

While a PCA origin of the ADS is most common, a similar branch arising from the SCA was identified in the original 1965 study (reporting an SCA anastomosis to the PCA dural branch in 1 cadaver $^{7}$ and reported in 5 patients with tentorial AVFs by Byrne and Garcia in $2013^{9}$ and later eponymously named as the artery of Wollschlaeger and Wollschlaeger by Tayebi Meybodi et al, ${ }^{10}$ in 2017. ${ }^{11}$ The literature is variable in describing the SCA dural branch as a variant of the ADS versus an entirely separate artery. ${ }^{9,11-13}$ Because we have previously described a tentorial AVF with a coexistent pial-to-dural arterial supply from both the PCA and SCA,${ }^{14}$ for the purposes of this study, we defined the ADS as being solely of PCA origin.

Endovascular treatment has become progressively prominent in the treatment of intracranial dural AVFs. ${ }^{15}$ The direct communication of the ADS between the dural arterial network and the intradural posterior circulation poses a potential risk of iatrogenic stroke related to reflux of liquid embolic agents toward pial vessels. ${ }^{2,9}$ Given the overall rarity of falcotentorial AVFs, the impact that the ADS supply has on the treatment of 


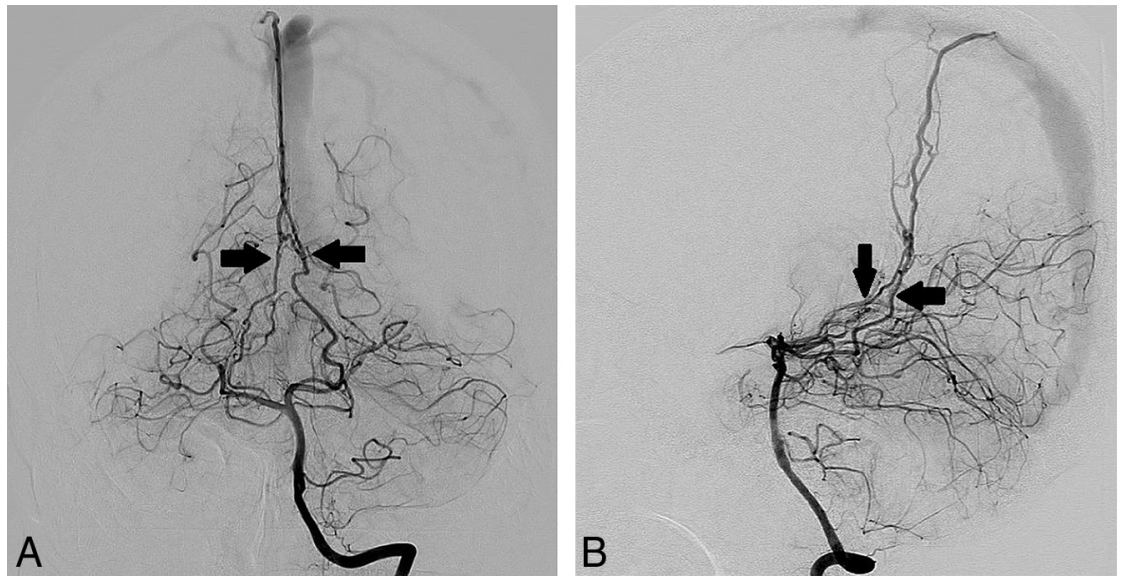

FIG 1. A, Cerebral DSA (patient 3) via a left vertebral artery injection demonstrating arterial supply to a superior sagittal sinus dural AVF by enlarged bilateral arteries of Davidoff and Schechter. Anterior-posterior projection in the arterial phase shows a bilateral enlarged ADS arising from the superior aspect of the Pl-2 junctions of the posterior cerebral arteries and converging (black arrows) into an enlarged falcine artery at the falcotentorial junction, with early venous filling of the superior sagittal sinus. Note the presence of cortical venous reflux. $B$, Lateral projection shows a bilateral enlarged ADS (black arrows) extending posteriorly along the free edges of the tentorium cerebelli and converging adjacent to the falcotentorial junction.

these fistulas is not well-described. In this study, we aimed to assess the angioarchitecture, treatment strategies, and clinical outcomes for intracranial dural AVFs that receive arterial supply from the ADS. This study builds on our previously published analysis of intracranial dural AVFs with a pial artery supply. ${ }^{14}$

\section{MATERIALS AND METHODS}

Ethics approval for this study was granted by the Research Ethics Board of the University Health Network, Toronto (approval No. 19-5018). Retrospective cohort review was undertaken of all patients with intracranial AVFs managed at Toronto Western Hospital between 2006 and 2018. Inclusion criteria were a confirmed diagnosis of dural AVF on DSA, follow-up time-resolved MRA or DSA after interventional or conservative management, and a demonstrated arterial supply to the AVF from ADS. Clinical presentation and clinical outcomes were obtained from the electronic patient records.

\section{Imaging Assessment}

Baseline and follow-up DSA (and MRA when available) imaging for each patient was analyzed independently by 2 reviewers, both fellowship-qualified in interventional neuroradiology (K.D.B. and H.K.). Disagreements were resolved by a senior reviewer (T.K.). The following characteristics were assessed on DSA: fistula location, arterial supply, venous drainage, classifications of Borden et $\mathrm{al}^{16}$ and Cognard et al, ${ }^{17}$ endovascular treatment approach, embolic agent used, number of endovascular procedures required, residual supply from the ADS after the first embolization, and final angiographic outcome.

\section{RESULTS}

\section{Diagnosis}

Between 2006 and 2018 at Toronto Western Hospital, 173 patients with 192 fistulas were identified with a confirmed diagnosis of dural AVF on DSA and follow-up imaging available. Of these, 6 patients ( 3 women and 3 men; mean age, 46.5 years) with 6 fistulas demonstrated arterial supply to the AVF from the ADS $(3.5 \%$ of patients, $3.1 \%$ of fistulas) (see On-line Table 1 for individual patient demographics, clinical presentations, and angiographic analysis results). One patient presented with subarachnoid hemorrhage. Four patients were diagnosed with falcotentorial fistulas (all Cognard type IV); 1 patient, with a parasagittal fistula (Cognard III); and 1 patient, with a superior sagittal sinus fistula (Cognard IIa + b) (Fig 1). Patients 1 and 6 were previously included in our published analysis of AVFs with pial artery supply. ${ }^{14}$

\section{Treatment Planning}

Following multidisciplinary discussion among radiosurgery, cerebrovascular neurosurgery, and interventional neuroradiology, the consensus opinion in all 6 cases was for initial endovascular transarterial embolization based on the angiographic features, the extensive vascular structures involved, the deep location, and the perceived natural history.

\section{Endovascular Treatment}

All 6 patients initially underwent transarterial embolization using liquid embolic agents (On-line Table 2). Three patients required a second embolization session, in part due to residual supply to the fistula from the ADS. Two patients specifically underwent microcatheter cannulation of the ADS (Figs 2 and 3), and patient 2 underwent embolization via the ADS. All patients demonstrated cure of the fistula on the final DSA (Figs $2 E,-F$ and $3 E$, $-F)$. No procedural complications were encountered; in particular, we did not encounter reflux to the PCA.

\section{DISCUSSION}

\section{Published Literature}

Based on our review of the literature, this is the largest reported series of dural AVFs supplied by the ADS treated by endovascular techniques (the existing literature predominantly being case reports; On-line Table 3). ${ }^{1-3,18}$ The ADS supply may not be appreciated on angiography due to competitive flow from multiple arterial feeders (Fig $3 A,-B$ ) and thus may not always have been recognized in large series of tentorial AVFs. ${ }^{9,19}$ Tentorial fistulas constitute $<3 \%$ of cranial AVFs but are 6 times more likely than nontentorial AVFs to present with hemorrhage, ${ }^{20}$ likely a result of the direct cortical venous drainage seen with these AVFs. $3,13,20$

\section{Surgical Approach to Falcotentorial AVFs}

Most tentorial AVFs carry a high risk of hemorrhage ${ }^{20}$ and endovascular approaches can be challenging; thus, some cases may require microsurgical disconnection. ${ }^{13,21}$ The primary surgical goal for tentorial AVFs is the same as for all AVFs-occlusion of 

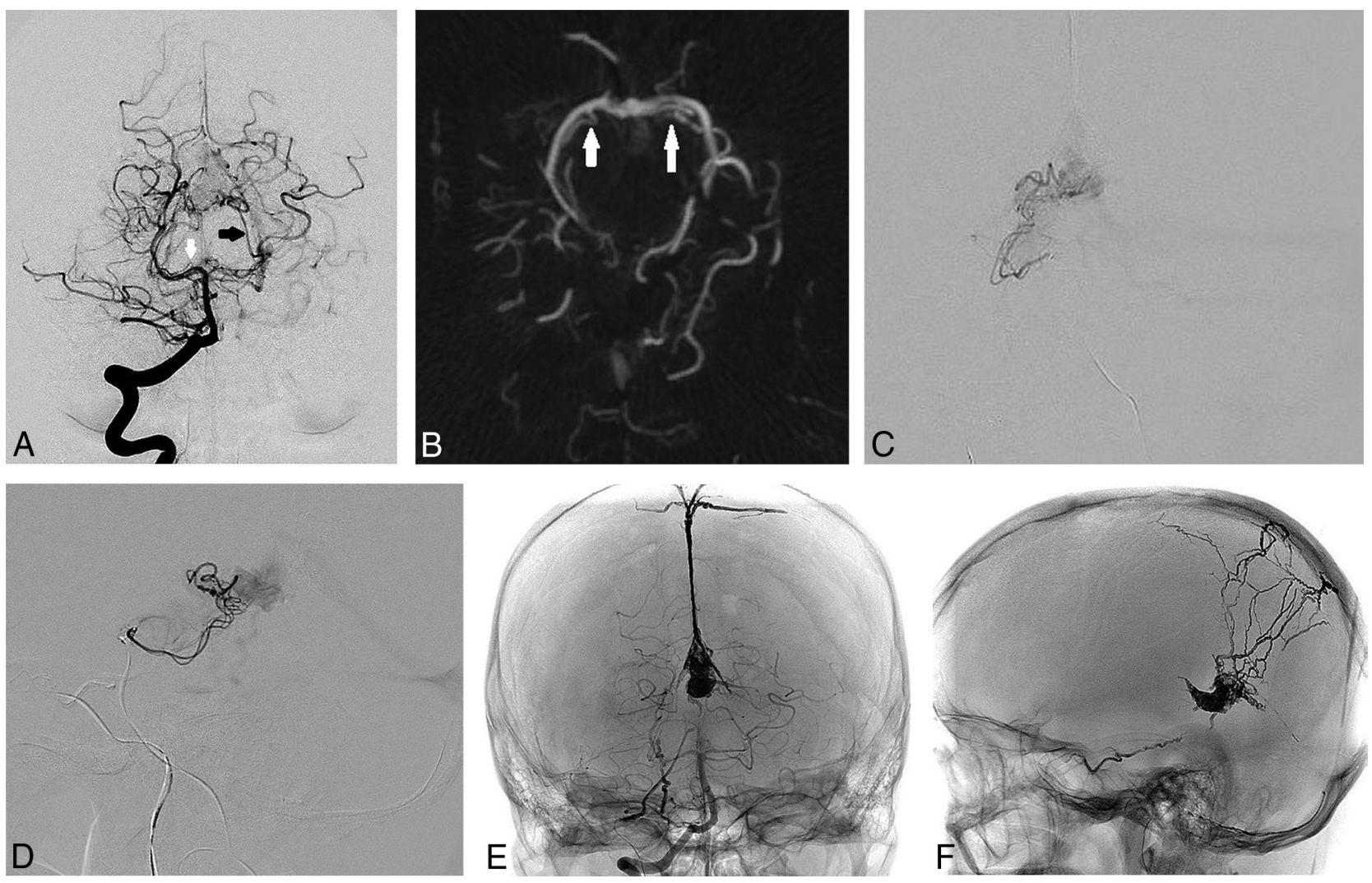

FIG 2. A, Cerebral DSA and endovascular treatment (patient 1) of a falcotentorial dural AVF supplied by the bilateral arteries of Davidoff and Schechter. Anterior-posterior projection of a right vertebral artery injection in the arterial phase shows an enlarged left ADS (black arrow) with early filling of the vein of Galen. Note the mildly enlarged right ADS arising from the right Pl-2 junction (white arrow) and the infratentorial venous reflux. $B$, Axial MIP reconstruction of a 3D rotational angiogram performed via right vertebral artery injection shows the bilateral origins of the ADS from the P1-2 junctions of the posterior cerebral arteries (white arrows). C, Anterior-posterior projection of a microcatheter injection within the right ADS shows early venous filling along the straight and left transverse sinuses. $D$, Lateral projection of a microcatheter injection within the right ADS shows the course of the vessel along the free edge of the tentorium to the falcotentorial junction, with early venous filling into the vein of Galen. E, Nonsubtracted anterior-posterior projection during right vertebral artery injection after a second-stage transvenous embolization shows no residual early venous filling, with an Onyx cast filling the vein of Galen. $F$, Spot lateral radiograph of the skull shows the Onyx cast following transarterial and transvenous embolizations.

the proximal portion of the draining vein. ${ }^{21}$ In principle, the operative strategy is based on an optimal surgical approach with an ideally adapted patient position allowing gravity to retract the brain, open subarachnoid planes, and shorten dissection times to expose and interrupt the draining vein. ${ }^{13,21}$

Lawton et $\mathrm{al}^{13}{ }^{13}$ in 2008 , created a surgical classification of tentorial AVFs based on their experience with 31 cases, differentiating 6 types based on fistula location, dural base, associated sinuses, and direction of venous drainage. Among those 31 patients, arterial supply from branches of the SCA or PCA (including the ADS) was identified in 8 patients. ${ }^{13}$ Six of these 8 patients had the Galenic subtype, located adjacent to the falcotentorial junction with drainage to the vein of Galen either directly or via cortical veins, requiring a posterior interhemispheric surgical approach after initial transarterial embolization. ${ }^{13}$ Preoperative embolization is often undertaken to minimize blood loss due to the extensive adjacent arterial and deep venous structures in the operative field. ${ }^{13,22}$ If a cure can be achieved by endovascular means, this may be preferable to a surgical approach. ${ }^{21}$

In our overall cohort of 173 patients with intracranial AVFs, only 4 patients had falcotentorial Galenic subtype AVFs ${ }^{13}$ (2.3\%).
All 4 patients demonstrated an ADS supply and were included in this study; this finding is consistent with the known high rates of SCA or PCA supply to this AVF subtype. ${ }^{13}$ All 4 patients underwent endovascular treatment with angiographic cure, and none required surgical intervention.

\section{Endovascular Approaches to Falcotentorial AVFs with ADS Supply}

Both transarterial ${ }^{2,3,18}$ and transvenous ${ }^{23}$ approaches with the use of liquid embolic agents have been described for the successful treatment of falcotentorial AVFs, with a treatment goal of occlusion of the fistulous point and foot of the draining vein to achieve cure. In our series, all patients initially underwent transarterial embolization using liquid embolics (On-line Table 2), with excellent outcomes, thus eliminating the need for potentially more invasive surgical approaches.

In patient 2, the initial embolization procedure also required microcatheter selection and embolization from the ADS itself (Fig 3) once competitive flow from the middle meningeal artery was excluded. In this instance, a highly distal position was achieved with the microcatheter, allowing deposition of small coils to minimize reflux followed by administration of Onyx 

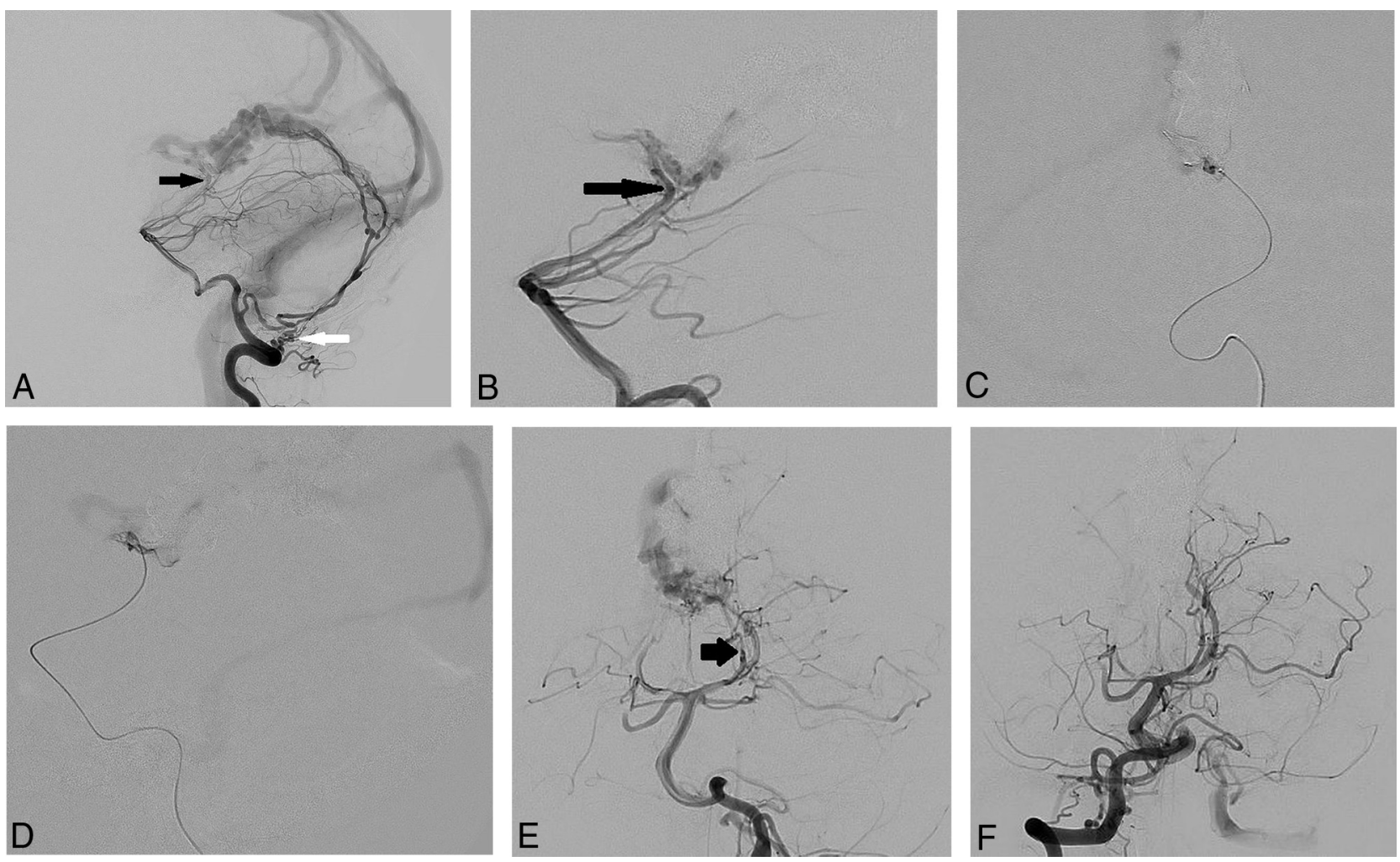

FIG 3. A, Cerebral DSA and endovascular treatment (patient 2) of a falcotentorial dural AVF supplied by the bilateral arteries of Davidoff and Schechter. Lateral projection of a left vertebral artery injection shows supply to the dural AVF by the left posterior meningeal artery (white arrow) and faint supply from the ADS (black arrow). B, Lateral projection of a left vertebral artery injection after embolization using Onyx from the posterior meningeal artery shows the residual ADS supply (black arrow) to the inferior surface of the vein of Galen more clearly, with reduced competitive flow. C, Anterior-posterior projection of a microcatheter injection via the left ADS distally shows the remnant fistulous flow to the junction of the vein of Galen and straight sinus at the falcotentorial junction. $D$, Lateral projection of a microcatheter injection via the left ADS distally shows the residual supply to the dural AVF with deep venous reflux. $E$, Anterior-posterior projection of a left vertebral artery injection in the arterial phase shows the residual supply to the dural AVF by the enlarged left ADS (black arrow). F, Anterior-posterior projection of a right vertebral artery injection after embolization of the left ADS distal supply using coils and Onyx shows no residual early venous filling with cure of the AVF.

Table: Risk-reduction strategies for endovascular treatment of falcotentorial dural AVFs

\begin{tabular}{|c|c|c|}
\hline Category & Risk-Reduction Strategy & $\begin{array}{l}\text { Patients } \\
\text { Treated }\end{array}$ \\
\hline \multirow{2}{*}{$\begin{array}{l}\text { Anatomic assessment; to } \\
\text { identify supply from } \\
\text { ADS }\end{array}$} & Magnified high-frame-rate angiography & $1-6$ \\
\hline & $\begin{array}{l}3 \mathrm{D} \text { rotational angiography with multiplanar } \\
\text { reconstructions }\end{array}$ & $1-6$ \\
\hline \multirow{2}{*}{$\begin{array}{l}\text { Transarterial } \\
\text { embolization; } \\
\text { strategies to avoid } \\
\text { reflux across ADS }\end{array}$} & $\begin{array}{l}\text { Initial embolization from non-ADS arterial supplies } \\
\text { (to reduce competitive flow) }\end{array}$ & $1-6$ \\
\hline & $\begin{array}{l}\text { Close monitoring for linear reflux anteriorly from the } \\
\text { vein of Galen (along the expected course of ADS) }\end{array}$ & $1-6$ \\
\hline \multirow{2}{*}{$\begin{array}{l}\text { Embolization directly via } \\
\text { ADS; strategies to } \\
\text { treat via ADS while } \\
\text { avoiding reflux }\end{array}$} & $\begin{array}{l}\text { Direct cannulation of ADS with embolization if distal } \\
\text { access achieved (pressure-cooker technique to } \\
\text { minimize reflux) }\end{array}$ & 2 \\
\hline & $\begin{array}{l}\text { Aborting embolization attempts from ADS if distal } \\
\text { access not achieved (insufficient safety margin) }\end{array}$ & 1 \\
\hline \multirow[t]{2}{*}{$\begin{array}{l}\text { Strategies for residual } \\
\text { ADS supply }\end{array}$} & $\begin{array}{l}\text { Staged embolization over multiple sessions as } \\
\text { required }\end{array}$ & $1,3,5$ \\
\hline & $\begin{array}{l}\text { Transvenous approach (eg, reverse pressure-cooker } \\
\text { technique) }\end{array}$ & 1 \\
\hline
\end{tabular}

cannulated with a microcatheter (Fig 2), but a distal position adjacent to the fistula could not be obtained. Our opinion was that successful injection of a liquid embolic agent from this proximal position would require initial formation of a long plug of embolic agent, thus increasing the risk of reflux into the PCA and basilar artery. This patient was subsequently cured by transvenous embolization.

\section{Impact of ADS Supply on the Endovascular Approach}

The key to avoiding reflux across the ADS was initial recognition of its supply to the AVF. Given the poten-

(Covidien, Irvine, California) directly to the fistulous point using a modified pressure-cooker technique. Understanding the complex arterial anatomy and using imaging-based treatment were the keys to a complete, safe, and successful endovascular treatment approach in this case. In patient 1 , the right ADS was tial difficulties of identifying the ADS supply when there is competitive flow (Fig 3) and the high likelihood of pial supply from the SCA or PCA to a Galenic-type tentorial AVFs, ${ }^{13}$ it would be reasonable to assume that most fistulas in this location have potential ADS supply. Therefore, care should be taken to assess 
the ADS supply with magnified, high-frame-rate DSA and MPRs of $3 \mathrm{D}$ rotational angiography (Fig $2 B$ ) when treating these fistulas. Even if such a supply is not identified, care should still be taken during embolization to assess any linear reflux anteriorly from the vein of Galen and along the expected course of the free tentorial edge, because this could represent reflux back toward the PCA and basilar artery. We have summarized the strategies we used to avoid dangerous reflux across ADS in the Table.

\section{Study Limitations}

This study is limited by the small sample size, retrospective design, and the already-discussed difficulties associated with identifying the ADS supply (potentially underestimating the true rate of supply). The requirement for follow-up imaging may have excluded patients with low-grade fistulas (less of a concern in tentorial AVFs, which are usually high-grade).

\section{CONCLUSIONS}

Dural AVFs supplied by the ADS are rare and difficult to treat by surgical or endovascular means. Endovascular treatment can be successfully undertaken by incorporating detailed anatomic assessment with risk-reduction strategies. Recognition of the ADS supply to falcotentorial junction fistulas is key to avoiding iatrogenic posterior circulation stroke.

Disclosures: Kartik D. Bhatia-UNRELATED: Employment: University Health Network, Toronto, Comments: Clinical Fellow in interventional neuroradiology. Vitor Mendes Pereira-UNRELATED: Consultancy: Stryker, Medtronic, Philips Healthcare, Balt, Cerenovus.* Timo Krings—UNRELATED: Consultancy: Stryker, Medtronic, Penumbra; Royalties: Thieme; Stock/Stock Options: Marblehead. *Money paid to the institution.

\section{REFERENCES}

1. Griessenauer CJ, Loukas M, Scott JA, et al. The artery of Davidoff and Schechter: an anatomical study with neurosurgical case correlates. Br J Neurosurg 2013;27:815-18 CrossRef Medline

2. Puri AS. Dural arteriovenous fistula supplied by the artery of Davidoff and Schechter. Radiol Case Rep 2010;5:375 CrossRef Medline

3. Gioppo A, Farago G, Caldiera V, et al. Medial tentorial dural arteriovenous fistula embolization: single experience with embolic liquid polymer SQUID and review of the literature. World Neurosurg 2017;107:1050.e1-57 CrossRef Medline

4. Hart JL, Davagnanam I, Chandrashekar HS, et al. Angiography and selective microcatheter embolization of a falcine meningioma supplied by the artery of Davidoff and Schechter: case report. $J$ Neurosurg 2011;114:710-13 CrossRef Medline

5. Uchino A, Ohno M. Cerebellar hemangioblastoma supplied by the artery of Davidoff and Schechter: a case report. Nihon Igaku Hoshasen Gakkai Zasshi 1986;46:1194-97 Medline

6. Martins C, Yasuda A, Campero A, et al. Microsurgical anatomy of the dural arteries. Neurosurgery 2005;56(2 Suppl):211-51; discussion 211-51 Medline
7. Wollschlaeger PB, Wollschlaeger G. An infratentorial meningeal artery [in German]. Radiologe 1965;5:451-52 Medline

8. Weinstein M, Stein R, Pollock J, et al. Meningeal branch of the posterior cerebral artery. Neuroradiology 1974;7:129-31 CrossRef CrossRef Medline

9. Byrne JV, Garcia M. Tentorial dural fistulas: endovascular management and description of the medial dural-tentorial branch of the superior cerebellar artery. AJNR Am J Neuroradiol 2013;34:1798804 CrossRef Medline

10. Tayebi Meybodi A, Vigo V, Lawton MT, et al. The artery of Wollschlaeger and Wollschlaeger: an anatomical-clinical illustration. Br J Neurosurg 2017;31:593-95 CrossRef Medline

11. Krafft PR, Liu SS, Agarwalla PK, et al. The meningeal branch of the superior cerebellar artery. Br J Neurosurg 2018;32:273-75 CrossRef Medline

12. Umeoka $\mathrm{K}$, Takusakawa $\mathrm{Y}$, Kominami $\mathrm{S}$, et al. The meningeal branches of the superior cerebellar artery: a surgical observation study. J Neurosurg 2016;124:244-47 CrossRef Medline

13. Lawton MT, Sanchez-Mejia RO, Pham D, et al. Tentorial dural arteriovenous fistulae: operative strategies and microsurgical results for six types. Neurosurgery 2008;62:110-24; discussion 124-25 Medline

14. Osada T, Krings T. Intracranial dural arteriovenous fistulas with pial arterial supply. Neurosurgery 2019;84:104-15 CrossRef Medline

15. Signorelli F, Gory B, Maduri R, et al. Intracranial dural arteriovenous fistulas: a review of their current management based on emerging knowledge. J Neurosurg Sci 2017;61:193-206 CrossRef Medline

16. Borden JA, Wu JK, Shucart WA. A proposed classification for spinal and cranial dural arteriovenous fistulous malformations and implications for treatment. J Neurosurg 1995;82:166-79 CrossRef Medline

17. Cognard C, Gobin YP, Pierot L, et al. Cerebral dural arteriovenous fistulas: clinical and angiographic correlation with a revised classification of venous drainage. Radiology 1995;194:671-80 CrossRef Medline

18. Choudhri O, Marks MP. Endovascular treatment of a tentorial dural arteriovenous fistula. Neurosurg Focus 2014;37:1 CrossRef Medline

19. Tomak PR, Cloft HJ, Kaga A, et al. Evolution of the management of tentorial dural arteriovenous malformations. Neurosurgery 2003;52: 750-60; discussion 760-62 CrossRef Medline

20. Hiramatsu M, Sugiu K, Hishikawa T, et al. Epidemiology of dural arteriovenous fistula in Japan: analysis of Japanese Registry of Neuroendovascular Therapy (JR-NET2). Neurol Med Chir (Tokyo) 2014;54:63-71 CrossRef Medline

21. Radovanovic I, Wallace M. Cranial dural arteriovenous fistula disconnection. In: Jandial R, McCormick P, Black P, eds. Core Techniques in Operative Neurosurgery. Philadelphia: Elsevier; 2019

22. Zhou LF, Chen L, Song DL, et al. Tentorial dural arteriovenous fistulas. Surg Neurol 2007;67:472-81; discussion 481-82 CrossRef Medline

23. Beer-Furlan A, Dasenbrock HH, Joshi KC, et al. Transarterial and transvenous approaches for embolization of tentorial dural arteriovenous fistula. Neurosurg Focus 2019;46(Suppl 2):V10 CrossRef Medline 
n the article “Artery of Davidoff and Schechter Supply in Dural Arteriovenous Fistulas" (AJNR Am J Neuroradiol 2020;41:300-04),

the institutional affiliations for T. Wälchli were listed incorrectly. The correct affiliations are as follows:

Joint Department of Medical Imaging and Division of Neurosurgery, Department of Surgery, Toronto Western Hospital, Toronto, Ontario, Canada.

Department of Fundamental Neurobiology, Krembil Research Institute, Toronto Western Hospital, University Health Network, University of Toronto, Toronto, Ontario, Canada.

Group of CNS Angiogenesis and Neurovascular Link, Neuroscience Center Zurich, University of Zurich, Swiss Federal Institute of Technology (ETH) Zurich, and University Hospital Zurich, Zurich, Switzerland.

Division of Neurosurgery, University Hospital Zurich, Zurich, Switzerland.

http://dx.doi.org/10.3174/ajnr.A6518 